\title{
O INTÉRPRETE COMO PRODUTOR DE SENTIDOS: UMA ANÁLISE DISCURSIVA DA ATIVIDADE DE INTERPRETAÇÃO FORENSE
}

\author{
Deusa Maria de Souza Pinheiro Passos*
}

RESUMO: A partir de uma perspectiva discursiva de linguagem, este artigo discute o papel do intérprete, objetivando refletir sobre representações imaginárias acerca da responsabilidade e de dilemas enfrentados por esse profissional em contexto jurídico. Tomando como base um corpus de gravações em áudio, o estudo analisa, em nível discursivo, algumas decisões tomadas pelo intérprete em audiências judiciais. Trata-se de um caso real envolvendo um processo de tráfico de entorpecentes, conduzido nas línguas portuguesa e inglesa. No presente estudo, ilustram-se tensões envolvidas nas escolhas linguísticas do intérprete forense e suas consequências práticas no processo de interpretação. A natureza dessas decisões contribui para o argumento principal deste trabalho: contemplar o lugar do intérprete como produtor de sentidos e não como mero decodificador de palavras.

UNITERMOS: interpretação forense; análise de discurso; imaginário; língua inglesa.

ABSTRACT: From a discursive perspective, this article aims at discussing the role of the interpreter, reflecting upon imaginary representations of his/her responsibility and dilemmas concerning Court Interpreting. Based on a corpus composed by audio recordings of hearings concerning a drug trafficking case in Brazil, this study

* Docente do Departamento de Letras Modernas, USP. Doutora em Linguística pela UNICAMP. 
examines some of the discursive decisions taken by the interpreter in order to illustrate tensions involved in his/ her linguistic choices with practical implications in the interpreting process. The nature of these decisions contributes to support the main argument in this study, i.e. consider the interpreter a producer of meanings and not a mere word decoder.

KEYWORDS: court interpreting; discourse analysis; imaginary; English language

Quando Boris Yeltsin fala através de um intérprete, queremos realmente ouvir a voz do intérprete? Ouvimos, com certeza, porque queremos saber o que Yeltsin tem a dizer. Consideramos, ou melhor, estamos preparados, somos condicionados a tomar a voz do intérprete como um "portador" sem substância própria, um veiculo virtualmente transparente. Qualquer coisa que fuja a essa transparência é considerado ruido. Ao mesmo tempo, sabemos que, a menos que entendamos russo, a voz do intérprete é tudo que temos. Não nos incomoda não ter acesso direto à língua de Yeltsin porque sabemos que podemos confiar no profissionalismo do intérprete. Acreditamos serem as palavras do intérprete cópia ou reprodução precisa e confiável das palavras de Yeltsin. Essa confiança permite-nos aceitar ou projetar o discurso do intérprete constituindo o equivalente ao discurso de Yeltsin. ${ }^{1}$

Theo Hermans, 1996

1 Tradução nossa. Reproduzimos, aqui, o texto original: When Boris Yeltsin speaks through an interpreter, do we really want to hear the speaker's voice? We listen, surely, because we want to know what Yeltsin has to say (...) we regard - or better: we are prepared, we have been conditioned to regard the interpreter's voice as a carrier without substance of its own, a virtually transparent vehicle. Anything that takes away from this transparency is unwelcome 'noise'. At the same time we know that unless we understand Russian, the interpreter's voice is all we have. We are not bothered about not having direct access to Yeltsin's language because

TradTERm, 15, 2009, p. 113-131 


\section{Introdução}

Este estudo visa, basicamente, a propor uma discussão a respeito do trabalho de um profissional sempre presente, embora pouco visto. Trata-se do Intérprete ${ }^{2}$, aquele individuo que, para o senso comum, promove o entendimento entre partes que, a priori, não conseguem estabelecer vínculo comunicativo entre si por não compreenderem umas as línguas das outras. Sua atuação dá-se por diversos moldes e abrange um rol heterogêneo de ocasiões que, por sua vez, variam de importância nos âmbitos histórico, político, econômico e social (Roland, 1999).

A literatura sobre Interpretação ${ }^{3}$ costuma defini-la como tradução oral de um discurso oral, em oposição à tradução oral de textos escritos. Intérpretes têm exercido papéis relevantes na história: a serviço de governos ou religiões, em expedições de exploração e invasão, no serviço militar ou diplomático.

Estudos sobre história da Interpretação são recentes. Acesso a atuações de Intérpretes no passado dá-se pelo exame de documentos escritos, na forma de cartas, diários e biografias do próprio intérprete, ou outros tipos de relatos escritos. Em virtude da ausência de registros mais confiáveis, muitas lacunas permanecem.

A atividade de Interpretação, como função oficial ou profissional, parece existir há muito tempo: alguns estudos indicam seu uso no antigo Egito. Sabe-se da circulação, em tempos antigos (em Roma, Egito e Grécia), de sentidos acerca da crença na superioridade de uma língua em relação a outra. Os antigos gregos, por exemplo, tinham pouco respeito pelas línguas de outras nações, referindo-se a elas como "bárbaras" (Delisle, 1995).

Embora haja relatos da atuação de Intérpretes na antiguidade, a necessidade de intérpretes cresceu e tornou-se reconhecida

we know we can trust the interpreter's professionalism. We trust that the interpreter's words are an accurate and truthful copy or reproduction of Yeltsin's words. This trust (...) allows us to accept, or to project, the interpreter's discourse as constituting the equivalent of Yeltsin's discourse.

2 Às vezes, também designado tradutor oral.

3 Interpretação (com inicial maiúscula) designa a atividade de tradução oral.

TradTerm, 15, 2009, p. 113-131 
somente a partir da Idade Média. No período renascentista, em relação ao estatuto da atividade, circulavam, também, sentidos sobre o papel que o Intérprete exercia na sociedade.

O argumento de que "intérpretes nascem intérpretes" prevaleceu de forma categórica até os tempos modernos. Enquanto o treino em línguas estrangeiras sempre esteve disponivel de uma forma ou de outra ao longo da história, o ensino de técnicas de Interpretação como atividade profissional iniciou-se somente no início do século XX (Delisle \& Woodsworth, 1995).

Quanto ao Intérprete, embora seu desempenho "técnico" tenha sido mais abordado apenas ultimamente por estudiosos do mundo inteiro, sua posição político-ideológica não tem motivado muitos estudos. Geralmente, enfoca-se o processo de Interpretação em si, por meio da avaliação de dispositivos e mecanismos considerados de cunho preponderantemente "técnico". Intérpretes costumam ser citados na literatura individualmente, em relação ao que eles apresentam de "fascinante": aspectos que os destacam como únicos e talentosos, seja pela excelente memória ("de computador"), com capacidade invejável para processar com rapidez a fala do "original" - sem mesmo recorrer a anotações -, seja pela qualidade de sua voz e dicção.

Pouco tem sido discutida, porém, a posição discursiva do Intérprete e sua presença nos processos dos quais participa. As discussões que mais se aproximam desse aspecto, em geral, abordam a questão do estresse sofrido pelo intérprete durante sua atuação e nos momentos que a precedem.

Se há, por vezes, controvérsias teóricas envolvendo a questão da natureza da voz do tradutor do texto impresso, a "visibilidade" do tradutor-intérprete é constitutiva do processo de Interpretação. Portanto, partimos do pressuposto da necessidade de se produzir uma reflexão que contemple a presença efetiva do Intérprete e o processo de configuração da visibilidade de seu lugar.

Uma das crenças que povoam o imaginário dos leigos, em especial, diz respeito ao fato de o intérprete conhecer - ou dever conhecer - tudo sobre todas as áreas do conhecimento humano. Como aponta Herbert (1952:23), "o intérprete ideal seria uma enciclopédia viva, constantemente atualizado em relação a tudo o que

TRadTERM, 15, 2009, p. 113-131 
é dito e feito em todos os setores da atividade humana"4. Essa visão ainda tem seduzido alguns intérpretes, os quais acreditam na possibilidade de alcançar tal ideal, chegando mesmo a afirmar compreenderem tudo o que ouvem, sendo capazes, como se diz no meio profissional, de "transmitir o recado" perfeitamente.

A ilusão do domínio sobre os conteúdos interpretados a partir do contato entre duas línguas produz efeitos, de modo particular, na Interpretação Forense ${ }^{5}$ - modalidade de interpretação consecutiva, não regulamentada como profissão, em contexto brasileiro.

$\mathrm{O}$ fato de um intérprete não ser solicitado, com frequência, a interpretar em contexto jurídico brasileiro não diminui a relevância dessa atividade. No Brasil, estudos acadêmicos sobre interpretação forense são praticamente inexistentes. Intérpretes em contexto jurídico costumam trabalhar sozinhos e raramente têm oportunidades para discutir sua prática com outros intérpretes, pois a maioria deles atua em duplas como intérpretes de conferência (na modalidade de Interpretação Simultânea).

O ceticismo de alguns intérpretes, no que concerne a pesquisas em interpretação, acreditando ser a prática a única maneira de melhorar sua performance, torna dificil o acesso a material ilustrativo do trabalho de intérpretes forenses.

\section{0 corpus de estudo}

Nosso corpus de estudo consiste em gravações em áudio de minha própria atuação como Intérprete, realizadas durante audiências na $37^{\mathrm{a}}$ Vara Criminal de São Paulo, ao longo de oito meses.

Como Intérprete freelance ${ }^{5}$, fui nomeada pelo reitor da universidade na qual sou docente para atuar num processo criminal, a pedido de um juiz do Fórum Criminal. Normalmente, somente profissionais registrados como Tradutor Juramentado/Intérprete Comercial são solicitados para atuarem em contexto legal. En-

\footnotetext{
4 Essa obra foi considerada por muito tempo uma espécie de "bíblia" dos intérpretes, utilizada como referência em cursos de Interpretação.

5 Minha tradução para a expressão em inglês Court Interpreting.
}

TradTerm, 15, 2009, p. 113-131 
118

tretanto, costuma constituir prática relativamente comum para órgãos da polícia e tribunais de justiça brasileiros a convocação de professores de inglês de escolas secundárias do estado, sem experiência em Interpretação, para darem assistência em audiências e julgamentos com depoimentos em línguas estrangeiras. Assim, serviços são fornecidos por pessoas sem adequada qualificação na área de Interpretação e, não raramente, sem nível de conhecimento linguístico satisfatório nas línguas estrangeiras (no caso, o inglês).

O processo judicial em questão envolvia o julgamento de seis homens, de nacionalidade nigeriana, e uma jovem brasileira, acusados de tráfico de entorpecentes. A interpretação foi realizada na modalidade consecutiva, português-inglês-português, pois os acusados nigerianos escolheram depor em inglês, embora essa não fosse sua lingua materna.

De acordo com os autos do processo, poderíamos resumir o caso da seguinte forma: o grupo de nigerianos e a moça brasileira haviam sido indiciados por policiais, representando o DENARC, uma divisão da polícia de São Paulo responsável pela investigação de crimes ligados ao narcotráfico.

\section{A versão da acusação}

De acordo com a polícia, os acusados haviam sido presos, em flagrante, vendendo cocaína na porta de um restaurante, no centro da cidade de São Paulo. Por meio de um telefonema anônimo para a polícia, um motorista de táxi reportou que nigerianos eram constantemente vistos vendendo drogas, disfarçados de funcionários de um restaurante. O motorista também forneceu o nome e a descrição física da moça brasileira. Após o telefonema, dois policiais se dirigiram à área próxima ao restaurante. Fazendo-se passar por usuários de drogas, abordaram a brasileira e solicitaram cocaína. Antes de mostrar a droga, a moça pede para ver o dinheiro. Ao passar a droga aos policiais, ela imediatamente recebe voz de prisão. Também, de acordo com os policiais, foi feito um acordo entre a brasileira e os policiais para que ela apontasse os demais traficantes e, em especial, o dono da droga.

TradTerm, 15, 2009, p. 113-131 


\section{A versão dos acusados}

Os acusados nigerianos alegaram terem sido presos como resultado de uma armadilha preparada pelos próprios policiais, motivada por discriminação racial e xenofobia, por serem negros e estrangeiros. De acordo com eles, as drogas haviam sido "plantadas" pelos policiais no restaurante e a polícia havia invadido uma festa durante a qual eles (os nigerianos) celebravam o aniversário da esposa do dono do estabelecimento. Segundo os acusados, quando a polícia entrou no restaurante, havia aproximadamente cem pessoas no local, dentre as quais quarenta brasileiras e algumas brancas. Empunhando metralhadoras e usando palavras de cunho racista, a polícia dispensou os convidados brasileiros e ordenou que todos os nigerianos permanecessem no local. Seis nigerianos foram presos e conduzidos à delegacia. A brasileira também foi presa porque, de acordo com os acusados, ela havia tentado defender seus amigos nigerianos que, por não falarem português, haviam sido insultados.

$\mathrm{Na}$ legislação brasileira, ofensas, como tráfico de drogas, encaixam-se na categoria dos chamados crimes hediondos, sendo, por essa razão, inafiançáveis, assim como crimes de estupro e sequestro, o que implica a detenção do acusado enquanto durar o processo.

Diferentemente do que acontece em países onde a interpretação forense é uma atividade relativamente bem estabelecida e reconhecida (Wadensjö, 1996; 1998), no Brasil ela se faz presente sobretudo em casos de tráfico de drogas envolvendo estrangeiros que não conhecem a língua portuguesa.

O termo "interpretação forense" é usado para referir todo e qualquer tipo de interpretação em contexto legal, sendo o tribunal somente um dos vários contextos em que a interpretação forense pode ocorrer (Halle, 1997). As atividades podem incluir entrevistas em delegacias de polícia, departamentos de alfândega, setores de imigração, assim como casos de divórcio, partilha de bens, adoções. No entanto, a interpretação que ocorre em tribunais tem ocupado posição de maior prestígio se comparada a outras interpretações legais. 


\section{0 papel da Interpretação em tribunais}

O que é traduzido para a língua do país durante uma audiência raramente é registrado, tampouco são realizadas transcrições do trabalho do Intérprete. Não há revisão dos autos para que os conteúdos interpretados sejam cotejados com sua transposição para a forma escrita. Tudo o que é dito no tribunal, na língua estrangeira, é transferido para os autos por meio da voz do juiz, na língua do país. Nas palavras de Morris,

a lei pressupõe não haver desvios no processo de interpretação. Tal crença permite ao tribunal funcionar efetivamente como um cenário monolingue, onde o que se declara na lingua estrangeira, quando traduzido para a lingua-alvo, torna-se o texto original. (Morris, 1995:27) ${ }^{6}$

Apreendemos, assim, a existência, por um lado, de uma visão de lingua como entidade transparente, sem equívocos ou desvios e, por outro, de uma concepção de significado como algo passível de ser plenamente alcançado entre os textos de saída e de chegada e, nesse caso, a tradução palavra por palavra não só é possivel como desejável. O "produto" do processo de interpretação é quase sempre tomado em relação de equivalência com o enunciado original e, portanto, válido legalmente.

Dessa forma, a língua alvo iguala-se (precisa igualar-se) à língua original, pela própria razão de ser do sistema judicial. Dito de outra forma, a Interpretação que se dá num tribunal não pode se constituir em forma de equívoco; não são permitidos ruídos, ou desvios. O sistema judicial não pode tolerar a presença de um "corpo estranho" à sua prática. Ele deve funcionar, para sua própria sobrevivência, como um "cenário monolíngue".

Esse efeito de originalidade transfere para o intérprete a expectativa de preencher determinados papéis e de pertencer a

6 the law assumes that no deviation is taking place in the interpreting process. This belief enables the court to function effectively as a monolingual setting, and what is stated in the foreign language when translated in the target language, becomes the original text. (Tradução nossa)

TradTERm, 15, 2009, p. 113-131 
certos lugares, já que dele se espera atuação eficiente e perfeita acuidade. Para o sistema judiciário, a atividade de Interpretação pode ser comparada à de um perito, de um técnico. Qualquer erro ou falha recai sobre as imperfeições humanas, ou seja, o próprio intérprete. Desse modo, a lei preserva sua credibilidade como instituição, imune a falhas e erros, enquanto o intérprete deverá assumir a responsabilidade por qualquer dificuldade encontrada ao longo do processo de Interpretação.

O intérprete ainda é visto como uma presença transparente, com uma única voz, neutra: "na visão de língua como algo transparente, um intérprete é uma não-pessoa” (Morris, 1996:10) ${ }^{7}$.

Essa crença de senso comum é também compartilhada pela maioria dos intérpretes cujo desejo é alcançar uma performance perfeita, ao tentarem transmitir sua compreensão dos significados e possíveis intenções do falante. Intérpretes inseridos no domínio legal tendem a adotar essa visão em virtude da natureza do seu trabalho, pois, de certa forma, ajudam a decidir sobre a vida de pessoas.

\section{Imaginário e direito à interpretação}

As condições prévias que sustentam a produção do discurso envolvem sempre a questão do imaginário (Pêcheux, 1975):

a) (i) A imagem que o locutor tem em relação ao ouvinte;

(ii) A imagem que o locutor pressupõe que o ouvinte faz dele;

b) (i) A imagem que o locutor faz do referente;

(ii) A imagem que o locutor pensa que o ouvinte faz do referente.

7 "in the transparent view of language, an interpreter is a non-person". (Tradução nossa)

TradTerm, 15, 2009, p. 113-131 
Poderíamos, assim, fazer referência a certas formações imaginárias que funcionam no discurso do intérprete e sobre o Intérprete. ${ }^{8}$

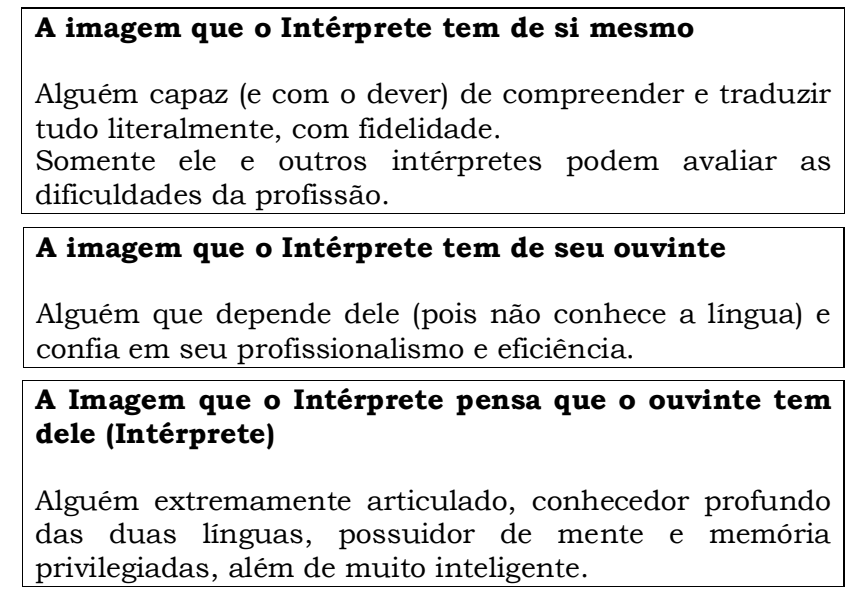

\begin{tabular}{l} 
A imagem que o intérprete tem da atividade de \\
interpretação \\
$\begin{array}{l}\text { Atividade que requer alto grau de especialização e } \\
\text { habilidades técnicas, que não pode ser exercida por } \\
\text { qualquer pessoa; requer dom. }\end{array}$ \\
\hline
\end{tabular}

A imagem que o intérprete pensa que o ouvinte tem
da atividade de interpretação
Atividade que requer alto grau de especialização e
habilidades técnicas, que não pode ser exercida por
qualquer pessoa; requer dom.

Parece haver um grupo de regras prescritivas (dos and don'ts) governando o processo imaginário que molda o papel do intérprete forense:

- Intérpretes não devem "melhorar" as declarações de testemunhas e acusados;

8 As formações imaginárias aqui elencadas foram apreendidas a partir de depoimentos de intérpretes atuando nas diversas modalidades de Interpretação (consecutiva e simultânea). Os depoimentos foram colhidos por meio de entrevistas e debates em listas de tradução na internet.

TradTerm, 15, 2009, p. 113-131 
- Intérpretes devem traduzir "literalmente", sem omitir, sem acrescentar ou fazer qualquer modificação de estilo ou conteúdo;

- Intérpretes não devem interromper quem fala;

- Intérpretes não devem pedir esclarecimentos quando juizes e advogados estão falando;

- Espera-se que intérpretes preencham lacunas, melhorem falhas ou erros da parte de juízes/advogados a fim de preservar a legitimidade e confiabilidade dos rituais e atividades do sistema judiciário;

- Espera-se que intérpretes traduzam e não interpretem, já que essa tarefa cabe a juízes e advogados.

Na literatura sobre Interpretação Forense (Edwards, 1995), há, inclusive, um código de ética geral a ser observado pelo intérprete quando ele se encontra num tribunal: (i) confidencialidade: manter sigilo sobre fatos ou assuntos revelados no tribunal; (ii) imparcialidade: não expressar sua opinião em hipótese alguma; (iii) isenção: manter-se fora do caso e restringir-se ao tempo de permanência no tribunal; (iv) mostrar-se disponível para admitir algum erro que por ventura possa cometer; (v) disponibilidade para lidar com constrangimentos.

Interpretar é algo que se espera de juristas, mas que é inapropriado para intérpretes forenses. A esse respeito, Collin comenta: "no tribunal, com frequência, advogados orientam intérpretes ('traduzam, não interpretem') como se traduzir representasse a aceitável atividade da palavra-por-palavra, ao passo que interpretar representaria o mesmo processo no qual advogados se engajam" (Collin, 1996:17) ${ }^{9}$.

"Traduza, não interprete" é a recomendação dirigida ao intérprete forense. Quais seriam as implicações, do ponto de vista

9 in court, lawyers often instruct interpreters, 'translate, don't interpret', as if translation is an acceptable word-for-word activity, while interpreting between two languages is the same process that lawyers engage in. (Tradução nossa) 
discursivo, desse enunciado tão familiar para o intérprete atuando em contexto jurídico?

A Interpretação é usualmente considerada tradução oral, referindo-se ao "mecanismo" de decodificação literal de uma língua à outra. Traduzir, nessa perspectiva, seria a possibilidade de encontrar (sempre), na língua de chegada, a forma linguística (léxico e sintaxe equivalentes) mais apropriada para a lingua de partida. Trata-se, acima de tudo, de alcançar e resgatar o "original", devolvendo-o com todos os seus sentidos verdadeiros na língua alvo, sem perdas. Investir na possibilidade do sentido literal é tomá-lo como pressuposto, podendo ser "encontrado" nas palavras, como se estivesse a elas "colado".

Para a Análise de Discurso, o sentido define-se na relação com a história, descartando a concepção de essência das palavras. O sentido não é um só, mas também não pode ser qualquer um, indiscriminadamente (Orlandi, 1996:27).

Para Orlandi, a noção de discurso confronta o esquema elementar que define mensagem: transmissão de informação mediante um processo linear onde os elementos-chave incluem emissor, receptor, código e referente, cabendo ao emissor a transmissão de uma mensagem e ao receptor sua decodificação:

...diremos que não se trata de transmissão de informação apenas, pois, no funcionamento da linguagem, que põe em relação sujeitos e sentidos afetados pela língua e pela história, temos um complexo processo de constituição desses sujeitos e produção de sentidos e não meramente transmissão de informação. (Orlandi, 1999:21)

O rito de um tribunal, ao contar com a presença do intérprete, reforça a própria concepção de linguagem como transparente e regula esquemas rígidos, a que o Intérprete deve se ajustar.

Quem teria o direito à interpretação ${ }^{10}$ ? Acredito que se trata do maior dilema enfrentado pelo intérprete forense (Morris, 1995; Collin, 1996). Imaginariamente concebido para atuar como mero

10 Interpretação (em itálico) refere-se ao conceito discutido por Orlandi, 1996.

TradTERm, 15, 2009, p. 113-131 
condutor de palavras, o intérprete é levado a encaixar-se no papel de agente objetivo e neutro. Toda escolha linguística está sob escrutínio dos interlocutores, podendo, por vezes, ser classificada como erro, sinal de negligência, ou ainda, ousadia. O princípio de neutralidade e desprendimento talvez esteja pressuposto na interpretação forense (Baker, 1998:34). O esforço do intérprete ao procurar "traduzir e não interpretar" é "interpretado" pelas autoridades que habitam o tribunal como sinal de "profissionalismo".

A crença em sentidos fornecidos a priori (o já-lá) alimenta a prática de certa "domesticação" de sentidos no contexto jurídico. As autoridades do sistema judicial (juízes, advogados, promotores), ao acreditarem ser o papel do intérprete de natureza meramente técnica (transferir sentidos, palavras de uma língua à outra), buscam exercer controle sobre a interpretação (tradução oral). Essas autoridades (e não os Intérpretes) estariam, assim, legitimadas a interpretar (atribuir sentidos).

Neste trabalho, buscaremos ilustrar, com um caso real, algumas das decisões tomadas em nivel discursivo, isto é, dilemas envolvendo escolhas linguísticas com consequências práticas no processo de Interpretação Forense. A natureza dessas decisões contribui para constituir o papel do intérprete, apesar de seu ilusório ${ }^{11}$ desejo de imparcialidade e senso de desprendimento no contexto jurídico.

No caso dos nigerianos, somente suas declarações foram traduzidas para o português, enquanto as declarações dos policiais responsáveis pelo indiciamento, e de outras testemunhas (ouvidas em português), não foram traduzidas para o inglês. Os nigerianos foram tratados com certo grau de "rejeição judicial" (juridical rejection (Morris, 1995)), na medida em que foram considerados elemento "estranho", não falantes de português, além de sofrerem uma atitude de quase "vingança" por parte de uma promotora em relação a uma testemunha de nacionalidade nigeriana incapaz de produzir evidência que comprovasse sua presença legal no Brasil ${ }^{12}$.

11 A meu ver, trata-se de uma ilusão necessária.

12 Fala da promotora (não traduzida para o inglês), dirigindo-se à testemunha nigeriana: "Vocês pensam que o Brasil é a casa da mãe Joana, onde vocês podem fazer o que quiserem?”

TradTerm, 15, 2009, p. 113-131 
De acordo com as leis brasileiras, uma pessoa acusada de algum crime tem a opção de declarar-se "culpada" ou "inocente". O acusado é considerado inocente até prova em contrário; somente a partir do veredito do juiz, com base nos autos de audiências e de júri, é que se define a situação do réu.

Consideremos, agora, exemplos de algumas formas através das quais - e até que ponto - a presença do intérprete é percebida no caso que escolhemos analisar. Optamos por destacar momentos nos quais os juízes dirigem-se ao intérprete.

O julgamento foi conduzido por três juízes, sendo um deles responsável pela elaboração e promulgação da sentença ao final do processo. Para efeito de análise, os designaremos por primeiro juiz, segundo juiz e terceiro juiz.

A) O Primeiro Juiz, parecendo desconhecer a natureza do trabalho do intérprete, pergunta-lhe:

Como é que a senhora gostaria de fazer, doutora?

No Brasil, durante um julgamento, antes de tomar o depoimento de acusado, o juiz lê em voz alta as acusações oficiais que pesam sobre ele e solicita a versão do acusado acerca do relato feito. Aqui, embora o juiz tenha, aparentemente, deixado para o Intérprete a decisão de lidar com a situação ("Como a senhora gostaria de fazer, doutora?"), os rituais do tribunal foram preservados e a leitura dos autos foi realizada na integra (aproximadamente quatro páginas) antes que a Interpretação pudesse ser feita.

B) O Segundo Juiz, presente na maioria das audiências e responsável pelo caso, perguntou ao Intérprete como seu colega (Primeiro juiz) havia lidado com a "parte em inglês" do julgamento:

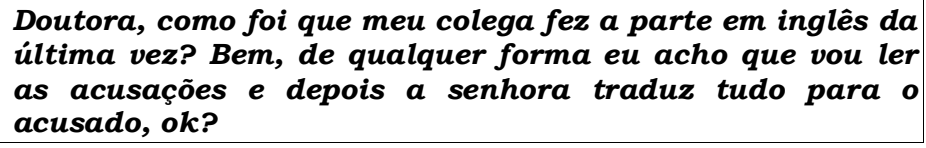

TradTerm, 15, 2009, p. 113-131 
Para o juiz, a "parte em inglês" do julgamento funcionava como componente "estranho" à rotina de um tribunal, e lhe parecia natural, de certa forma, adotar a abordagem de seu colega. A presença de um intérprete não se configura nesse contexto somente como exceção aos trabalhos do tribunal, mas também como símbolo do "novo" (embora esporádico), merecedor de observação. É comum a presença de "curiosos" (funcionários do Fórum, advogados estagiários etc) em audiências com Intérpretes. Da observação de um elemento "novo" que compõe um "quase show", passa-se ao monitoramento do desempenho do intérprete.

C) Antes da audiência, o Terceiro Juiz (no caso, uma juíza) consultou o Intérprete acerca da real incapacidade dos acusados de compreender o português. Quando a juíza oficialmente iniciou os trabalhos naquele dia, dirigiuse aos acusados da seguinte forma:

Vocês estão no Brasil, traficando drogas, então eu sei que vocês entendem português. You speak Portuguese (em inglês)

E ao Intérprete, em português:

Doutora, agora a senhora pode traduzir isso a eles em inglês, para que não reste nenhuma dúvida. Diga-lhes, também, que eu sou a juiza aqui e que eles devem se manter em silêncio a menos que eu lhes peça para falar.

Avaliando a atitude da juíza como antiética, o Intérprete reformulou o que a juíza havia dito em português e dirigiu-se aos acusados da seguinte forma: 


\section{I: As you live in Brazil, you probably understand Portuguese. You should remain silent unless I ask you to speak.}

(Como vocês moram no Brasil, vocês provavelmente entendem $\mathrm{o}$ português. Vocês deverão permanecer em silêncio, a menos que eu peça que falem.)

Esse momento poderia ser interpretado como um dilema para o intérprete, pois, embora a regra prescritiva diga que o intérprete não deve "permitir que sua opinião influencie sua atuação", a mesma regra prescritiva diz ao intérprete para "melhorar toda e qualquer falha da parte do juiz".

No exemplo citado, o intérprete omitiu "vocês estão no Brasil, traficando drogas", o que indica omissão de parte da fala da juíza. Assim, observamos as seguintes reformulações da fala "original":

\begin{tabular}{|l|l|}
\hline JUIZ & INTÉRPRETE \\
\hline $\begin{array}{l}\text { eu sei que vocês entendem } \\
\text { português }\end{array}$ & $\begin{array}{l}\text { vocês provavelmente entendem } \\
\text { português }\end{array}$ \\
\hline
\end{tabular}

\begin{tabular}{|l|l|}
\hline JUIZ & INTÉRPRETE \\
\hline $\begin{array}{l}\text { vocês estão no Brasil, traficando } \\
\text { drogas }\end{array}$ & $\begin{array}{l}\text { as you live in Brazil/ como } \\
\text { vocês moram no Brasil... }\end{array}$ \\
\hline
\end{tabular}

\begin{tabular}{|l|l|}
\hline JUIZ & INTÉRPRETE \\
\hline $\begin{array}{l}\text { Diga-lhes, também, que eu sou a } \\
\text { juiza aqui... }\end{array}$ & Enunciado omitido. \\
\hline $\begin{array}{l}\ldots \text { e que eles devem se manter em } \\
\text { silêncio a menos que eu lhes peça } \\
\text { para falar. }\end{array}$ & $\begin{array}{l}\text { You should remain silent unless I } \\
\text { ask you to speak. (Vocês deverão } \\
\text { permanecer em silêncio, a menos } \\
\text { que eu peça que falem.) }\end{array}$ \\
\hline
\end{tabular}

Uma avaliação inicial a partir do monitoramento da atuação do intérprete poderia levar-nos a afirmar que as reformulações do discurso jurídico original revelam falta de profissionalismo do intérprete, de experiência ou até mesmo de conhecimento da língua estrangeira. Várias "explicações" poderiam ser produzidas para justificar as mudanças constatadas no fio do discurso do Intérpre-

TradTerm, 15, 2009, p. 113-131 
te em relação à fala do juiz. Para o contexto jurídico, o exemplo em questão poderia ser interpretado como falha do profissional-intérprete, uma vez que passa pelo imaginário do como um Intérprete "deva" ser a crença de que ele conhece a língua estrangeira e é capaz de traduzir para a língua do tribunal.

Por outro lado, a omissão das formulações "traficando drogas" e "eu sou a juíza aqui", acaba, de certa maneira, "poupando" os acusados e o próprio juiz, "melhorando" a fala daquele que enuncia do lugar da autoridade, além de contribuir para preservar a credibilidade da instituição jurídica. Há muitas evidências num tribunal que não deixam dúvidas quanto a quem ocupa o lugar de juiz. Além disso, enunciar "vocês estão no Brasil traficando drogas" significa promulgar a sentença antes que o julgamento seja concluido, que todas as partes tenham sido ouvidas e seus relatos analisados. Tal gesto, advindo do lugar autorizado a falar em nome da lei, pode significar a negação da própria atividade jurídica em sua possibilidade constitutiva de julgar e eventualmente determinar formas de punição para ações humanas.

\section{Considerações finais}

Do ponto de vista de um analista de discurso, acreditamos que questões de linguagem revelam algumas das complexidades e tensões presentes nas condições de produção da atividade de Interpretação, com efeitos para a formação do Intérprete.

Uma abordagem da interpretação forense deveria dar prioridade a uma perspectiva descritiva mais do que prescritiva. Oportunidades deveriam ser criadas para que o Intérprete pudesse refletir criticamente sobre sua própria prática, deslocando a fixidez de sentidos atrelada a listas de regras a serem seguidas, quase no padrão "camisa-de-força".

O Intérprete jamais é neutro, invisivel ou transparente. Ao interpretar, ele movimenta sentidos entre linguas, produzindo efeitos sobre seus interlocutores. Uma interpretação não coincide com sua fonte; em sentido algum ela é equivalente ou idêntica ao dizer original.

O Intérprete não se insere numa tradição que contemple reflexão sobre sua prática, uma vez que ser Intérprete significa ser

TradTerm, 15, 2009, p. 113-131 
130

profissional, não falhar. Assim, analisar seu próprio saber-fazer é, muitas vezes, admitir o fracasso em satisfazer a própria razão de ser de seu trabalho.

É preciso desconstruir a ilusão da coincidência do dizer, da transparência da linguagem e da equivalência entre discursos, refletindo sobre o papel do Intérprete não só como membro ativo dos processos dos quais participa, mas também como produtor de sentidos e não, ao contrário do que muitos acreditam, como um mero decodificador de palavras.

\section{Referências bibliográficas}

BAKER, M. (ed.) (1998) Routledge Encyclopedia of Translation Studies. London: Routledge.

COLLIN, J. \& R. MORRIS (1996) Interpreters and the Legal Process. Winchester: Westerside Press.

DELISLE, J. \& J. WOODSWORTH (eds.) (1995) Translation through History. Amsterdam/Philadelphia: John Benjamins/Unesco Publishing.

EDWARDS, A.B. (1995) The Practice of Court Interpreting. Amsterdam/ Philadelphia: John Benjamins.

HALE, S. (1997) The Treatment of Register Variation in Court Interpreting. The Translator - Studies in Intercultural Communication. Manchester: St Jerome Publishing, 3:1, pp. 39-54.

HERBERT, J. (1952) The Interpreters Handbook: How to Become a Conference Interpreter. Genève: Librarie de l'Université, Georg \& Cie S.A.

HERMANS, T. (1996) The Translator's Voice in Translated Narrative. Target. Amsterdam: John Benjamins, vol. 8, n. 1, pp. 23-48.

MORRIS, R. (1995) The Moral Dilemmas of Court Interpreting. The Translator - Studies in Intercultural Communication. Manchester: St Jerome Publishing, 1:1, pp. 25-46.

ORLANDI, E.P. (1996) Interpretação: autoria, leitura e efeitos do trabalho simbólico. Petrópolis, RJ: Vozes.

(1999) Análise de Discurso: princípios e procedimentos. Campinas, SP: Pontes.

ROLAND, A R. (1999) Interpreters as Diplomats - A Diplomatic History of the Role of Interpreters in World Politics. Canada: University of Ottawa Press.

TradTerm, 15, 2009, p. 113-131 
WADENSJÖ, C. (1996) The Bilingual Courtroom: Court Interpreters in the Judicial Process (Berk-Seligson) and Fundamentals of Court Interpretation: Theory, Policy and Practice (González, Vásques \& Mikkelson) Review article. The Translator - Studies in Intercultural Communication. Manchester: St Jerome Publishing, 2:1, pp. 104-109. (1998) Interpreting as Interaction. New York, USA: Addison Wesley Longman.

TradTerm, 15, 2009, p. 113-131 